\title{
BMJ
}

\section{Partial protection of seasonal trivalent inactivated vaccine against novel pandemic influenza A/H1N1 2009: case-control study in Mexico City}

\begin{abstract}
Lourdes Garcia-Garcia, research professor, 'Jose Luis Valdespino-Gómez, epidemiologist, ${ }^{2}$ Eduardo LazcanoPonce, research professor, ${ }^{1}$ Aida Jimenez-Corona, research professor, ${ }^{1}$ Anjarath Higuera-Iglesias, epidemiologist, ${ }^{3}$ Pablo Cruz-Hervert, research professor, ${ }^{1}$ Bulmaro Cano-Arellano, engineer, ${ }^{1}$ Antonio GarciaAnaya, engineer, ${ }^{1}$ Elizabeth Ferreira-Guerrero, epidemiologist, ${ }^{1}$ Renata Baez-Saldaña, research professor, ${ }^{1}$ Leticia Ferreyra-Reyes, research professor, ${ }^{1}$ Samuel Ponce-de-León-Rosales, infectious diseases specialist, ${ }^{2}$ Celia Alpuche-Aranda, infectious diseases specialist, ${ }^{4}$ Mario Henry Rodriguez-López, research professor, Rogelio Perez-Padilla, research professor, ${ }^{3}$ Mauricio Hernandez-Avila, epidemiologist ${ }^{5}$
\end{abstract}

\begin{abstract}
${ }^{1}$ Instituto Nacional de Salud Pública, Cuernavaca, Mor, Mexico 2Laboratorios de Biológicos y Reactivos de México (BIRMEX) Amores 1240, Col Del Valle, Delegación Benito Juárez. CP 03100, Distrito Federal, Mexico

${ }^{3}$ Instituto Nacional de Enfermedades Respiratorias (INER), Distrito Federal, México

${ }^{4}$ Instituto de Diagnóstico y Referencia Epidemiológicos (InDRE), Distrito Federal, Mexico

${ }^{5}$ Subsecretariat of Health Prevention and Promotion, Distrito Federal, Mexico Correspondence to: J L Valdespino jvaldespinog@birmex.gob.mx
\end{abstract}

Cite this as: BMJ 2009;339:b3928 doi:10.1136/bmj.b3928

\section{ABSTRACT}

Objective To evaluate the association of 2008-9 seasonal trivalent inactivated vaccine with cases of influenza $\mathrm{A} / \mathrm{H} 1 \mathrm{~N} 1$ during the epidemic in Mexico.

Design Frequency matched case-control study. Setting Specialty hospital in Mexico City, March to May 2009.

Participants 60 patients with laboratory confirmed influenza A/H1N1 and 180 controls with other diseases (not influenza-like illness or pneumonia) living in Mexico City or the State of Mexico and matched for age and socioeconomic status.

Main outcome measures Odds ratio and effectiveness of trivalent inactivated vaccine against influenza A/H1N1.

Results Cases were more likely than controls to be admitted to hospital, undergo invasive mechanical ventilation, and die. Controls were more likely than cases to have chronic conditions that conferred a higher risk of influenza related complications. In the multivariate model, influenza A/H1N1 was independently associated with trivalent inactivated vaccine (odds ratio $0.27,95 \%$ confidence interval 0.11 to 0.66 ) and underlying conditions $(0.15,0.08$ to 0.30$)$. Vaccine effectiveness was $73 \%$ (95\% confidence interval $34 \%$ to $89 \%$ ). None of the eight vaccinated cases died.

Conclusions Preliminary evidence suggests some protection from the 2008-9 trivalent inactivated vaccine against pandemic influenza A/H1N1 2009, particularly severe forms of the disease, diagnosed in a specialty hospital during the influenza epidemic in Mexico City.

\section{INTRODUCTION}

From April to June 2009, reported confirmed cases of influenza due to the novel influenza $\mathrm{A} / \mathrm{H} 1 \mathrm{~N} 1$ virus led the World Health Organization to raise the alert level of influenza pandemic from phase 3 to phase 6 . In less than two months the spread of the virus worldwide indicated the start of the 2009 influenza pandemic.
Up to 6 July 2009, 122 countries had officially reported 94512 laboratory confirmed cases. ${ }^{1}$

The new virus may have started in Mexico and southern California. ${ }^{2}$ Between 1 March and 29 May 2009, the Mexican national system of surveillance identified 41998 people with acute respiratory tract disease, of whom $25127(59.8 \%)$ were tested. Of these, $5337(21.2 \%)$ were identified as having the novel $\mathrm{A} / \mathrm{H} 1 \mathrm{~N} 1$ virus using real time reverse transcriptase polymerase chain reaction assay. By 29 May 2009, 97 people had died. ${ }^{3}$ The start of the outbreak was marked by three separate events that occurred in Mexico City, San Luis Potosi, in central Mexico, and Mexicali, near the border with the United States; by late April suspected clinical cases had been reported in 19 of the 32 states in Mexico. ${ }^{45}$ Epidemiological evidence indicated that the outbreak peaked nationally in late April, although localised cases continue to be identified. $^{3}$

The viral genomic sequence for several of the novel $\mathrm{A} / \mathrm{H} 1 \mathrm{~N} 1$ strains, including a Mexican isolate, has been made publicly available. ${ }^{6}$ Given the new reassortant nature of this virus - that is, unusual mixing of swine, avian, and human influenza genetic sequences - the available evidence, although incomplete, suggests that seasonal vaccines will confer little or no protection against influenza $\mathrm{A} / \mathrm{H} 1 \mathrm{~N} 1 .^{7}$ Mexican guidelines recommend vaccination with trivalent inactivated influenza vaccine (virus strains A/Brisbane/59/2007 (H1N1)-like, A/Brisbane/10/2007 (H3N2)-like, and $\mathrm{B} /$ Florida/4/2006-like antigen) for children aged 6-35 months, all adults aged more than 60 , and individuals older than 35 months with conditions conferring a higher risk of influenza related complications. ${ }^{8} \mathrm{We}$ evaluated the association of 2008-9 seasonal trivalent inactivated vaccine with cases of influenza $\mathrm{A} / \mathrm{H} 1 \mathrm{~N} 1$ in a specialty hospital in Mexico City during the influenza epidemic. 


\section{METHODS}

The National Institute of Respiratory Diseases is a 178 bed specialty hospital that provides outpatient and hospital care for uninsured people of low and medium socioeconomic status living mostly in Mexico City and its surrounding states-mainly the State of Mexico. Although the institute is a specialty hospital, it sometimes functions as a primary healthcare facility because of the poor system for referral.

From 29 March to 20 May 2009 we carried out a retrospective frequency matched case-control study.

\section{Definition of cases and controls}

Cases were people who had been admitted to hospital or been seen as outpatients at the National Institute of Respiratory Diseases and had a clinical diagnosis of influenza and a respiratory tract specimen that tested positive for novel influenza $\mathrm{A} / \mathrm{H} 1 \mathrm{~N} 1$ by real time reverse transcriptase polymerase chain reaction assay. We included in the study consecutive confirmed cases diagnosed during the study period. All the cases lived in Mexico City or the State of Mexico.

Controls were people who lived in Mexico City or the State of Mexico and had received medical care at the National Institute of Respiratory Diseases for a clinical diagnosis other than influenza during the study period. We excluded patients with suspected influenza or pneumonia or those who were prescribed antiviral treatment.

We frequency matched the cases and controls by age (years, <5, 5-20, 21-40, 41-60, and >60) and socioeconomic strata (low, medium, and high). Controls were obtained by randomly sampling three times the number of cases within each category from a list, including all patients who had received medical care at the hospital during the study period. The patients recruited as controls and those excluded were not significantly different for age, sex, or socioeconomic status.

Trained staff used a chart abstraction tool to collect information from patients' clinical files. Two of the authors (LGG, RBS) checked the data to ensure quality, completeness, and validity. Information was collected on age, sex, socioeconomic status, address, telephone number, medical conditions, admission to hospital, use of invasive mechanical ventilation, and clinical outcome. Socioeconomic status was as recorded in the clinical charts and based on the social workers' evaluation, on the basis of annual income and formal education of each household member, number in household, and characteristics of the household. ${ }^{9}$

For both cases and controls we investigated trivalent inactivated influenza vaccination for the 2008-9 winter season by face to face or telephone interview of the patients or close relatives. Trained staff interviewed patients using a set of prespecified items to ensure the accuracy of vaccine status (date and place of vaccination, type of vaccine, other vaccines administered during the same year). Interviewers were not blinded to the status of cases or controls.

\section{Laboratory confirmation of influenza $\mathrm{A} / \mathrm{H} 1 \mathrm{~N} 1$ cases}

The collection of samples and laboratory confirmation has been described. ${ }^{10}$ Briefly, nasopharyngeal specimens were collected at admission using a swab and bronchial aspirate samples were obtained after tracheal intubation. Samples were placed in transport medium and kept at $2-4^{\circ} \mathrm{C}$. Real time reverse transcriptase polymerase chain reaction assay was carried out at the National Microbiology Laboratory in Winnipeg, Canada; the Centers for Disease Control and Prevention in Atlanta, USA; or the Instituto de Diagnostico y Referencia Epidemiologicos, Mexico, in accordance with published guidelines from the US Centers for Disease Control and Prevention. ${ }^{11}$

\section{Analysis}

We used conditional logistic analyses to compare the characteristics of the cases and controls and estimated crude odds ratio and 95\% confidence intervals whenever possible. To evaluate the efficiency of frequency matching we compared the distribution of socioeconomic strata between cases and controls. The binomial test was used to compare the prevalence of conditions conferring a higher risk of influenza related complications between surviving and non-surviving cases. We also used the binomial test to determine if the proportion of patients who required invasive mechanical ventilation or died among vaccinated and unvaccinated cases differed significantly. We compared vaccination status and the distribution of underlying conditions between cases and controls by age group using conditional logistic analyses and estimated crude odds ratio and $95 \%$ confidence interval whenever possible.

After adjusting for sex and underlying conditions, we modelled the association between influenza vaccination and novel influenza $\mathrm{A} / \mathrm{H} 1 \mathrm{~N} 1 \mathrm{using}$ conditional logistic regression analysis. We analysed vaccination status as a categorical measure of exposure, with vaccinated as referent. Variables were entered into the models according to their significance in bivariate analysis $(\mathrm{P} \leq 0.10)$ and their biological relevance. We also used conditional regression analysis to model the association between vaccine status and influenza $\mathrm{A} / \mathrm{H} 1 \mathrm{~N} 1$ after adjusting for sex and underlying conditions for each of the five age groups.

The adjusted odds ratio was used to estimate vaccine effectiveness using the formula (1-adjusted odds ratio $) \times 100$, as recommended in a previous study. ${ }^{12}$

We estimated the power of the study on the basis of the design, $\alpha=0.05$, number of cases, number of controls per case, observed frequency of vaccination among controls, observed correlation coefficient, and observed odds ratio.

\section{Sensitivity analysis}

We used conditional regression analysis to model the association between vaccination and influenza $\mathrm{A} / \mathrm{H} 1 \mathrm{~N} 1$ and estimated vaccine effectiveness by including only cases and controls who had been admitted to hospital. We also modelled the association 
Table 1|Admission diagnoses of 180 controls ${ }^{\star}$

\begin{tabular}{lc}
\hline Diagnosis & No $(\%)$ of controls $(\mathrm{n}=180)$ ) \\
Elective ear, nose, or throat surgery & $73(41)$ \\
\hline Asthma & $51(28)$ \\
\hline Obstructive sleep apnoea & $22(12)$ \\
\hline Chronic obstructive pulmonary disease & $16(9)$ \\
\hline Gastro-oesophageal reflux & $11(6)$ \\
\hline Tuberculosis & $11(6)$ \\
\hline HIV/AlDS & $10(6)$ \\
\hline Arterial hypertension & $8(4)$ \\
\hline Interstitial pneumopathy & $7(4)$ \\
\hline Diabetes & $6(3)$ \\
\hline Lung cancer & $5(3)$ \\
\hline Chronic haemoptysis & $5(3)$ \\
\hline Chronic heart disease & $4(2)$ \\
\hline Pleural disease & $4(2)$ \\
\hline Obesity & $4(2)$ \\
\hline Bronchiectasis & $3(2)$ \\
\hline Systemic autoimmune disease & $3(2)$ \\
\hline Thoracic surgery & $3(2)$ \\
\hline Pulmonary arterial hypertension & $3(2)$ \\
\hline Pneumocystis jirovecii pneumonia & $3(2)$ \\
\hline Congenital thoracic deformity & $2(1)$ \\
\hline Tracheal stenosis & $2(1)$ \\
\hline Chronic renal insufficiency & $2(1)$ \\
\hline Pulmonary nodule & $2(1)$ \\
\hline Pulmonary sequestration & $1(0.6)$ \\
\hline Elective tracheostomy & $1(0.6)$ \\
\hline Pulmonary embolism & $1(0.6)$ \\
\hline Bronchiolitis & $1(0.6)$ \\
\hline Hepatic cirrhosis & $1(0.6)$ \\
\hline Tormatitis & $1(0.6)$ \\
\hline
\end{tabular}

*Four patients had four diagnoses, 13 had three, 52 had two, and the remainder $(n=111)$ had one.

between vaccination status and influenza $\mathrm{A} / \mathrm{H} 1 \mathrm{~N} 1$ by conditional regression analysis adjusting for sex in the subset of patients without underlying conditions. We used Stata 9.0.

\section{RESULTS}

Overall, 60 confirmed cases of influenza A/H1N1 and 180 controls were identified. The controls were admitted to the outpatient clinic or to hospital for a total of 270 diagnoses (table 1): four patients had four diagnoses, 13 had three, 52 had two, and the remainder $(\mathrm{n}=111)$ had one. The 10 most common reasons for admission were elective ear, nose, or throat surgery; asthma; obstructive sleep apnoea; chronic obstructive pulmonary disease; gastro-oesophageal reflux; tuberculosis; HIV/AIDS; arterial hypertension; interstitial pneumopathy; and diabetes.

Controls who had been vaccinated against 2008-9 seasonal influenza were significantly more likely than cases to refer (table 2). Most of the cases $(n=38,63 \%)$ were aged 21-60 years. Frequency matching ensured that the cases and controls were balanced for socioeconomic status (table 2). Cases and controls were also similar for sex.

The cases had more severe clinical manifestations than the controls; they were more likely to be admitted to hospital, undergo invasive mechanical ventilation, and die. Most of the cases had been previously healthy $(\mathrm{n}=45,75 \%)$. Overall, the controls were significantly more likely than the cases to have underlying conditions conferring a higher risk of influenza related complications (table 2). With the exception of diabetes, which was three times more prevalent among cases than among controls $(7(12 \%)$ v $6(3 \%), \mathrm{P}=0.02)$, compared with cases the prevalence of other conditions among controls was higher or not significantly different.

The prevalence of underlying conditions conferring a higher risk of influenza related complications was similar among surviving and non-surviving cases $(10 / 42(24 \%)$ v $5 / 18 \quad(28 \%), \mathrm{P}=0.75)$. Conditions among the 10 surviving cases included chronic renal insufficiency, obesity, congenital thoracic deformity, and chronic obstructive pulmonary disease (one each); asthma $(\mathrm{n}=2)$; diabetes $(\mathrm{n}=3)$; and diabetes, obesity, and chronic renal insufficiency $(n=1)$. Conditions among the five cases who died included chronic obstructive pulmonary disease, obstructive sleep apnoea, and HIV/AIDS (one each); diabetes and pulmonary arterial hypertension $(n=1)$; and diabetes and obstructive sleep apnoea $(\mathrm{n}=1)$.

The proportion of patients who died among vaccinated cases was significantly lower than among unvaccinated cases $(0 / 8(0 \%) v 18 / 52(35 \%), \mathrm{P}=0.047)$. The proportion of patients requiring invasive mechanical ventilation was also lower among vaccinated cases than among unvaccinated cases, although this was not significant $(1 / 8(13 \%) v 25 / 52(48 \%), \mathrm{P}=0.058)$.

Table 3 shows the number of cases and controls and information on vaccination status and prevalence of underlying conditions by age group. With the exception of the age group 5-20 years, the crude odds ratio for vaccination during the previous season showed a protective effect for all age groups, although this was not statistically significant. The prevalence of underlying conditions conferring a higher risk of influenza related complications was significantly greater among controls aged $<5,41-60$, and more than 60 . When individual conditions were analysed by age group, asthma was significantly more prevalent among controls aged 5-20 and 21-40, whereas diabetes was significantly more prevalent among cases aged 21-40.

In the multivariate model, vaccination status and underlying conditions were independently associated with influenza $\mathrm{A} / \mathrm{H} 1 \mathrm{~N} 1$ (table 4). When the association of influenza $\mathrm{A} / \mathrm{H} 1 \mathrm{~N} 1$ with vaccine status for each age group was modelled, the adjusted odds ratio continued to show a protective effect, although this was statistically significant only for the age group 41-60 (table 3). Vaccine effectiveness against laboratory confirmed cases of influenza A/H1N1 was 73\% (95\% confidence interval $34 \%$ to $89 \%$ ). 
Table 2 |Personal and clinical characteristics of influenza A/H1N1 cases and controls. Values are numbers (percentages) unless stated otherwise

\begin{tabular}{|c|c|c|c|c|}
\hline Characteristics & $\begin{array}{l}\text { Cases } \\
(n=60)\end{array}$ & $\begin{array}{l}\text { Controls } \\
(n=180)\end{array}$ & $\begin{array}{l}\text { Crude odds ratio } \\
(95 \% \mathrm{Cl})^{\star}\end{array}$ & $P$ value \\
\hline Vaccinated & $8(13)$ & $53(29)$ & $0.344(0.149$ to 0.793$)$ & 0.012 \\
\hline Men & $32(53)$ & $106(59)$ & $0.797(0.442$ to 1.436$)$ & 0.5 \\
\hline Low socioeconomic status & $34(57)$ & $105(58)$ & 一 & $0.8 \dagger$ \\
\hline \multicolumn{5}{|l|}{ Age group (years): } \\
\hline$<5$ & $10(17)$ & $30(17)$ & 一 & - \\
\hline $5-20$ & $7(12)$ & $21(12)$ & 一 & - \\
\hline $21-40$ & $18(30)$ & $54(30)$ & - & - \\
\hline $41-60$ & $20(33)$ & $60(33)$ & 一 & - \\
\hline$>60$ & $5(8)$ & $15(8)$ & 一 & - \\
\hline Admitted to hospital & $59(98)$ & $61(34)$ & 129 (17 to 968) & $<0.001$ \\
\hline Invasive mechanical ventilation & $26(43)$ & $4(2)$ & 37.28 (11.88 to 117.02$)$ & $<0.001$ \\
\hline Deaths & $18(30)$ & $2(1)$ & - & $<0.001 \dagger$ \\
\hline Underlying conditionsł: & $15(25)$ & $120(67)$ & 0.17 (0.09 to 0.32$)$ & $<0.001$ \\
\hline Asthma & $2(3)$ & $51(28)$ & 0.07 (0.02 to 0.32$)$ & 0.001 \\
\hline Obstructive sleep apnoea & $2(3)$ & $22(12)$ & 0.24 (0.05 to 1.06$)$ & 0.06 \\
\hline $\begin{array}{l}\text { Chronic obstructive } \\
\text { pulmonary disease }\end{array}$ & $1(2)$ & $16(9)$ & 0.14 (0.02 to 1.19) & 0.07 \\
\hline Diabetes & $7(12)$ & $6(3)$ & 3.90 (1.24 to 12.28$)$ & 0.02 \\
\hline Gastro-oesophageal reflux & 0 & $11(6)$ & - & $0.07 \dagger$ \\
\hline HIV/AIDS & $1(2)$ & $10(6)$ & 0.28 (0.03 to 2.25$)$ & 0.2 \\
\hline Interstitial pneumopathy & $0(0)$ & $7(4)$ & 一 & $0.2 \dagger$ \\
\hline Obesity & $2(3)$ & $4(2)$ & 1.53 (0.26 to 8.79) & 0.6 \\
\hline Lung cancer & $0(0)$ & $5(3)$ & - & $0.3 \dagger$ \\
\hline Chronic heart disease & $0(0)$ & $4(2)$ & 一 & $0.5 \dagger$ \\
\hline Chronic renal insufficiency & $2(3)$ & $2(1)$ & 3.00 (0.42 to 21.29$)$ & 0.2 \\
\hline Other§ & $2(3)$ & $14(8)$ & & \\
\hline
\end{tabular}

${ }^{*}$ Calculated using conditional logistic regression.

†Fisher's exact test.

$\ddagger$ Medical conditions conferring a higher risk of influenza related complications. Three controls had three conditions; 26 controls two conditions; one case diabetes, chronic renal insufficiency, and obesity; and one case diabetes and obstructive sleep apnoea.

$\S B$ ronchiectasis (three controls), congenital thoracic deformity (one case, two controls), tracheal stenosis (two controls), pulmonary arterial hypertension (one case, three controls), systemic autoimmune disease (three controls), elective tracheostomy (one control).

\section{DISCUSSION}

The influenza vaccine used for the winter of 2008-9 in the northern hemisphere contained the trivalent vaccine virus strains A/Brisbane/59/2007 (H1N1)-like, A/Brisbane/10/2007 (H3N2)-like, and B/Florida/4/ 2006-like antigen. The Mexican Public Health Institutions provided trivalent inactivated influenza vaccine as part of the national vaccination programme. This study presents clinical data suggesting that this vaccine may provide some protection against influenza $\mathrm{A} / \mathrm{H} 1 \mathrm{~N} 1$, diagnosed in a specialty hospital during the epidemic of the novel influenza virus in Mexico. Moreover, that none of the vaccinated cases of influenza A/H1N1 died, indicates that seasonal vaccination might protect against the most severe forms of the disease.

These results are to be considered cautiously and in no way indicate that seasonal vaccine should replace vaccination against pandemic influenza $\mathrm{A} / \mathrm{H} 1 \mathrm{~N} 1$ 2009. Our data support the hypothesis that partial protection provided by the seasonal vaccine may be explained by the boosting of existing antibodies that were elicited by previous exposure, through either infection or vaccination, to an influenza $\mathrm{A} / \mathrm{H} 1 \mathrm{~N} 1$ virus genetically and antigenically more closely related to the novel influenza virus than contemporary seasonal H1N1 strains. In fact, the impact of seasonal vaccine over protection against pandemic influenza induced by pandemic influenza vaccine is presently being studied in different clinical trials by the National Institutes of Health and other agencies (http://clinicaltrials.gov/).

Previous studies focusing on seasonal vaccine offering cross protection against antigenically differing influenza strains occurring in epidemics indicate some level of protection. One study showed a small boost in cross reactive antibodies (measured by hemagglutination inhibition analysis) against A/Swine/Iowa $1930 \mathrm{~A} / \mathrm{H} 1 \mathrm{~N} 1$ and $1918 \mathrm{HA} / \mathrm{NA}$ recombinant virus among 15 volunteers vaccinated with A/New Caledonia/20/1999 A/H1N1. ${ }^{13}$ Cross protection against the $1968 / 1969$ pandemic influenza virus provided by the 1967 vaccines was evaluated during an outbreak among military staff. Polyvalent vaccine, 1967 formula, contributed towards preventing disease in those who did not receive the pandemic vaccine. ${ }^{14}$ During the present 2009 epidemic, the Centers for Disease Control studied serum cross protection afforded by seasonal vaccines against the novel influenza A/H1N $1 .{ }^{15}$ Using stored serum specimens from previous vaccine studies, the researchers assessed the level of cross reactive antibody to the novel influenza $\mathrm{A} / \mathrm{H} 1 \mathrm{~N} 1$ virus in cohorts of children aged 6 months to 9 years $(n=28)$, adults aged $18-59(n=30)$, and adults aged more than $60(n=42)$ before and after vaccination with the 2005-6, 2006-7, 2007-8, and 2008-9 seasonal vaccines against influenza. Results suggested that some immunity to the novel strain may exist among adults, especially among those aged more than 60 . After vaccination in adults, $7 \%$ aged $18-40,25 \%$ aged $18-64$, and $43 \%$ aged more than 60 had microneutralisation titres of 160 or more to the new virus, which was the estimated protective titre. cination status was modelled among the subset of case $(\mathrm{n}=45)$ and controls $(\mathrm{n}-60)$ without high risk underlying conditions, it continued to be significant (table 4). The estimated vaccine effectiveness for this subset was $86 \%$ (50\% to $96 \%$ ) 
Table 3 |Vaccination status and prevalence of underlying medical conditions conferring a higher risk of influenza related complications, by age group

\begin{tabular}{|c|c|c|c|c|c|c|}
\hline Characteristics by age group & No (\%) cases & No (\%) controls & Crude odds ratio $(95 \% \mathrm{Cl})^{*}$ & $P$ value & Adjusted odds ratio $(95 \% \mathrm{Cl}) \dagger$ & $P$ value \\
\hline \multicolumn{7}{|l|}{$<5$ years ( 10 cases, 30 controls) } \\
\hline Vaccinated & $4(40.0)$ & $16(53.3)$ & 0.59 (0.14 to 2.49$)$ & 0.5 & 0.4 (0.06 to 3.10$)$ & 0.4 \\
\hline Underlying conditionsf: & $2(20.0)$ & $26(86.7)$ & 0.05 (0.01 to 0.29$)$ & 0.001 & - & - \\
\hline Asthma & $1(10.0)$ & $13(43.3)$ & $0.16(0.02$ to 1.36$)$ & 0.09 & - & - \\
\hline Obstructive sleep apnoea & $1(10.0)$ & $10(33.3)$ & 0.23 (0.03 to 2.05$)$ & 0.2 & - & - \\
\hline Gastro-oesophageal reflux & 0 & $4(13.3)$ & - & $0.6 \S$ & - & - \\
\hline Interstitial pneumopathy & 0 & $1(3.3)$ & - & $1 \S$ & - & - \\
\hline Chronic heart disease & 0 & $1(3.3)$ & - & $1 \S$ & - & - \\
\hline \multicolumn{7}{|l|}{$5-20$ years ( 7 cases, 21 controls) } \\
\hline Vaccinated & $1(14.3)$ & $3(14.3)$ & $1(0.08$ to 12.85$)$ & 1 & $0.5(0.02$ to 10.95$)$ & 0.7 \\
\hline Underlying conditions*: & $2(28.6)$ & $15(71.4)$ & 0.19 (0.03 to 1.13$)$ & 0.07 & - & - \\
\hline Asthma & 1 (14.3) & $14(66.7)$ & $0.1(0.01$ to 0.92$)$ & 0.04 & - & - \\
\hline Chronic heart disease & 0 & $1(4.8)$ & - & $1 \S$ & - & - \\
\hline Chronic renal insufficiency & 1 (14.3) & 0 & - & $0.3 \S$ & - & - \\
\hline Other & 0 & $1(4.8)$ & - & $1 \S$ & - & - \\
\hline \multicolumn{7}{|l|}{$21-40$ years (18 cases, 54 controls) } \\
\hline Vaccinated & $1(5.6)$ & $12(22.2)$ & $0.21(0.03$ to 1.73$)$ & 0.1 & 0.25 (0.03 to 2.19$)$ & 0.2 \\
\hline Underlying conditions*: & $6(33.3)$ & $31(57.4)$ & $0.37(0.12$ to 1.15$)$ & 0.1 & - & - \\
\hline Asthma & 0 & $14(25.9)$ & - & $0.02 \S$ & - & - \\
\hline Obstructive sleep apnoea & 0 & $5(9.3)$ & - & $0.3 \S$ & - & - \\
\hline Chronic obstructive pulmonary disease & 0 & $1(1.9)$ & - & $1 \S$ & - & - \\
\hline Diabetes & $4(22.2)$ & 0 & - & $0.003 \S$ & - & - \\
\hline Gastro-oesophageal reflux & 0 & $3(5.6)$ & - & $0.6 \S$ & - & - \\
\hline HIV/AIDS & $1(5.6)$ & $8(14.8)$ & 0.35 (0.04 to 2.93$)$ & 0.3 & - & - \\
\hline Interstitial pneumopathy & 0 & $1(1.9)$ & - & $1 \S$ & - & - \\
\hline Obesity & $2(11.1)$ & $2(3.7)$ & $3.32(0.42$ to 26.16$)$ & 0.3 & - & - \\
\hline Lung cancer & 0 & $1(1.9)$ & - & $1 \S$ & - & - \\
\hline Chronic renal insufficiency & $1(5.6)$ & 0 & - & $0.3 \S$ & - & - \\
\hline Other & $1(5.6)$ & $6(11.1)$ & 0.48 (0.05 to 4.18$)$ & 0.5 & - & - \\
\hline \multicolumn{7}{|l|}{$41-60$ years ( 20 cases, 60 controls) } \\
\hline Vaccinated & $1(5.0)$ & $18(30.0)$ & 0.13 (0.01 to 1.00$)$ & 0.05 & 0.05 (0.006 to 0.53$)$ & 0.01 \\
\hline Underlying conditions*: & $4(20.0)$ & $36(60.0)$ & $0.17(0.05$ to 0.57$)$ & 0.004 & - & - \\
\hline Asthma & 0 & $10(16.7)$ & - & $0.06 \S$ & - & - \\
\hline Obstructive sleep apnoea & $1(5.0)$ & $5(8.3)$ & 0.59 (0.065 to 5.23$)$ & 0.6 & - & - \\
\hline Chronic obstructive pulmonary disease & $1(5.0)$ & $8(13.3)$ & 0.35 (0.04 to 2.92$)$ & 0.3 & - & - \\
\hline Diabetes & $3(15.0)$ & $5(8.3)$ & $1.92(0.42$ to 8.77$)$ & 0.4 & - & - \\
\hline Gastro-oesophageal reflux & 0 & $3(5.0)$ & - & $0.6 \S$ & - & - \\
\hline HIV/AIDS & 0 & $2(3.3)$ & - & $1 \S$ & - & - \\
\hline Interstitial pneumopathy & 0 & $3(5.0)$ & - & $0.6 \S$ & - & - \\
\hline Obesity & 0 & $2(3.3)$ & - & $1 \S$ & - & - \\
\hline Lung cancer & 0 & $3(5.0)$ & - & $0.6 \S$ & - & - \\
\hline Chronic heart disease & 0 & $2(3.3)$ & - & $1 \S$ & - & - \\
\hline Chronic renal insufficiency & 0 & $1(1.7)$ & - & $1 \S$ & - & - \\
\hline Other & 0 & $5(8.3)$ & - & $0.3 \S$ & - & - \\
\hline \multicolumn{7}{|l|}{$>60$ years ( 5 cases, 15 controls) } \\
\hline Vaccinated & $1(20.0)$ & $4(26.7)$ & $0.65(0.05$ to 8.97$)$ & 0.7 & 0.37 (0.01 to 11.64$)$ & 0.6 \\
\hline Underlying conditions*: & $1(20.0)$ & $12(80.0)$ & 0.08 (0.01 to 0.87$)$ & 0.04 & - & - \\
\hline Obstructive sleep apnoea & 0 & $2(13.3)$ & - & $1 \S$ & - & - \\
\hline Chronic obstructive pulmonary disease & 0 & $7(46.7)$ & - & $0.1 \S$ & - & - \\
\hline Diabetes & 0 & $1(6.7)$ & - & $1 \S$ & - & - \\
\hline Gastro-oesophageal reflux & 0 & $1(6.7)$ & - & $1 \S$ & - & - \\
\hline Interstitial pneumopathy & 0 & $2(13.3)$ & - & $1 \S$ & - & - \\
\hline Lung cancer & 0 & $1(6.7)$ & - & $1 \S$ & - & - \\
\hline Chronic renal insufficiency & 0 & $1(6.7)$ & - & $1 \S$ & - & - \\
\hline Other & $1(20.0)$ & $1(6.7)$ & $3.46(0.18$ to 67.64$)$ & 0.4 & - & - \\
\hline
\end{tabular}

*Calculated using conditional logistic regression.

†Conditional logistic regression used to control for sex and underlying medical conditions conferring a higher risk for influenza complications.

$\ddagger$ Medical conditions conferring a higher risk of influenza related complications.

§Fisher's exact test. 


\begin{tabular}{|c|c|c|}
\hline Characteristic & $\begin{array}{l}\text { Adjusted odds ratio } \\
\qquad(95 \% \mathrm{Cl})\end{array}$ & $P$ value \\
\hline \multicolumn{3}{|l|}{ Participants (60 cases, 180 controls): } \\
\hline Vaccinated $v$ unvaccinated (2008-9 winter season) & $0.27(0.11$ to 0.66$)$ & 0.004 \\
\hline Men & $0.72(0.37$ to 1.37$)$ & 0.3 \\
\hline Underlying conditions* & $0.15(0.08$ to 0.30$)$ & $<0.001$ \\
\hline \multicolumn{3}{|l|}{ Participants admitted to hospital (59 cases, 61 controls): } \\
\hline Vaccinated $v$ unvaccinated (2008-9 winter season) & $0.23(0.07$ to 0.78$)$ & 0.018 \\
\hline Men & $0.85(0.37$ to 1.97$)$ & 0.7 \\
\hline Underlying conditions* & $0.20(0.09$ to 0.45$)$ & $<0.001$ \\
\hline \multicolumn{3}{|c|}{ Participants with no underlying conditions* (45 cases, 60 controls): } \\
\hline Vaccinated $v$ unvaccinated (2008-9 winter season) & $0.14(0.04$ to 0.50$)$ & 0.003 \\
\hline Men & $0.73(0.31$ to 1.73$)$ & 0.479 \\
\hline
\end{tabular}

*Medical conditions conferring a higher risk of influenza related complications.

With few exceptions ${ }^{16}$ studies indicate protection ranging from $18.8 \%$ to $90 \%$ among children and healthy young adults ${ }^{17-22}$ against severe outcomes when seasonal influenza vaccine strains are not antigenically well matched to circulating endemic strains. Vaccine effectiveness varies considerably depending on study population (age, associated diseases, number of vaccine doses, and access to vaccine), specificity of outcome (medically attended acute respiratory tract disease, laboratory confirmed influenza, pneumonia associated admissions to hospital or deaths, or seroconversion to circulating influenza virus strains), and circulating strains. In this study we dealt with some of these confounders by frequency matching for age and socioeconomic status and by adjusting for sex and chronic underlying conditions in the analysis.

Influenza A/H1N1 viruses circulated in humans from 1918 until 1957, when they were replaced by the A/H2N2 virus; they reappeared in $1977 .{ }^{23}$ Noticeably, the similarity of $\mathrm{A} / \mathrm{H} 1 \mathrm{~N} 1$ viruses in 1977 to viruses circulating in 1950 explained substantial immunity among adults aged 27 or more who been exposed to these viruses and illnesses mainly in the younger population. ${ }^{24}$ Thereafter, $\mathrm{A} / \mathrm{H} 1 \mathrm{~N} 1$ virus did not replace the preceding H3N2 subtype. Therefore the two influenza A subtypes, H1N1 and H3N2, have cocirculated with influenza B viruses since 1977, and current trivalent inactivated vaccines contain representatives of each A subtype and B virus. Antigens on the human $\mathrm{A} / \mathrm{H} 1 \mathrm{~N} 1$ virus have evolved considerably since 1972, leading to several changes in the A/H1N1 component of the vaccine. ${ }^{24}$ The novel A/H1N1 2009 virus contains a unique combination of gene segments from both North American and Eurasian swine lineages. ${ }^{25}$ Using post-infection ferret antisera tested by haemagglutination inhibition assay, researchers have found this virus to be antigenically similar to classical swine $\mathrm{A} / \mathrm{H} 1 \mathrm{~N} 1$ virus as well as to North American lineage triple reassortant $\mathrm{A} / \mathrm{H} 1 \mathrm{~N} 1$ viruses that have circulated in swine since the late 1990s in the United States and that have occasionally infected humans. ${ }^{25}$
The lack of similarities between this virus and its closest relatives emphasises the lack of surveillance in swine populations that may harbour influenza virus with pandemic potential and the possibility of its unidentified transmission to humans.

\section{Limitations of the study}

Our study has several limitations, inherent to retrospective studies. The distribution and prevalence of diagnoses among controls on admission reflects the kind of patients who are admitted to the National Institute of Respiratory Diseases, a centre specialising in respiratory diseases and not a general hospital. Therefore the prevalence of chronic conditions conferring a higher risk of influenza related complications was high among the controls and thus their chance of having been vaccinated was higher than in the general population. Among our control population the frequency of influenza vaccination during the previous season by age group (64\% for children aged 6-35 months, 38\% for children aged 3-9 years, and 19\% for adults older than 50) was lower than vaccination coverage reported nationally $(72 \%, 64 \%$, and $78 \%$, respectively). Since national estimates for vaccination coverage were not available for young people and adults aged 10-49, we modelled the association between vaccine status and influenza $\mathrm{A} / \mathrm{H} 1 \mathrm{~N} 1$ for each age group. Results showed that the association between vaccine status and influenza $\mathrm{A} / \mathrm{H} 1 \mathrm{~N} 1$ continued to be protective, although this was statistically significant only for those aged 41-60. Wide confidence intervals were probably due to small sample sizes.

We consider that cases and controls originated from the same source population as cases of influenza $\mathrm{A} / \mathrm{HINI}$ and controls were drawn from the same geographical area-Mexico City and the State of Mexico, which had the majority of notifications for influenza during the study period. ${ }^{3}$ Therefore the controls had the same probability of being exposed to infective individuals as cases. Frequency matching allowed us to obtain a similar distribution of potential confounders (age and socioeconomic status) between cases and controls. Socioeconomic level may serve as an indicator of access to health services (as has been shown by previous studies)..$^{2627}$

Most of the cases of influenza $\mathrm{A} / \mathrm{H} 1 \mathrm{~N} 1$ had severe disease, which is understandable given that the National Institute of Respiratory Diseases is a hospital specialising in respiratory diseases and that surveillance was focused on more severe cases. Therefore we focused on cases with more severe clinical manifestations, estimated to be $6 \%$ of the total number of cases in Mexico. ${ }^{28}$ All but one of the cases of influenza A/H1N1 were admitted to hospital compared with $34 \%$ of the controls. We consider this comparison to be a valid one as most of the transmission of influenza occurred out of the hospital - that is, was not hospital acquired. Sensitivity analyses showed that the vaccine was effective for the subset of cases and controls who were admitted to hospital and for patients with no underlying conditions conferring a higher risk of 


\section{WHAT IS ALREADY KNOWN ON THIS TOPIC}

From April to June 2009, reported confirmed cases of influenza due to novel influenza

A/H1N1 led WHO to raise the alert level of influenza pandemic from phase 3 to 6

Several uncertainties surround this new pathogen

Non-clinical evidence, although incomplete, suggests that seasonal influenza vaccines will confer little or no protection against this novel virus

\section{WHAT THIS STUDY ADDS}

Preliminary evidence suggests some protection of 2008-9 trivalent inactivated vaccine against pandemic influenza A/H1N1 2009, particularly severe forms of the disease

This study is prone to limitations, however, because of the small sample size and the retrospective study design

Estimates for vaccine effectiveness could be inflated because of the high prevalence of chronic conditions and vaccination in our control population

influenza related complications. We included only laboratory confirmed cases of influenza $\mathrm{A} / \mathrm{H} 1 \mathrm{~N} 1$ to increase the specificity of our case definition. Similarly, we excluded cases with suspected influenza or pneumonia and patients receiving antivirals from our control group. As we were unable to match for underlying conditions conferring a higher risk of influenza related complications, we adjusted for this variable in the analyses. Influenza vaccination during the previous winter was investigated by trained staff using a standardised format to reduce the bias associated with self reported vaccine status; however, interviewers were not blinded to the status of cases and controls. Vaccine status was not, however, recorded on the medical charts so it was not possible to check the self reported information.

\section{Conclusions}

Our study provides preliminary evidence suggesting some protection from the 2008-9 trivalent inactivated vaccine against pandemic influenza A/H1N1 2009, particularly severe forms of the disease, diagnosed in a specialty hospital during the epidemic in Mexico City. Notwithstanding this contribution to protection, a specific vaccine against A/H1N1 2009 is crucial. In the coming months, seasonal and pandemic influenza vaccines will become available around the world. ${ }^{29}$ Prospective studies need to investigate the impact of seasonal vaccination over the immunological response elicited by pandemic A/H1N1 2009 vaccine.

Although this study provides preliminary evidence of a protective effect of seasonal vaccination against influenza $\mathrm{A} / \mathrm{H} 1 \mathrm{~N} 1$ virus, it is prone to limitations due to small sample size and the retrospective study design. Therefore the estimates for vaccine effectiveness could be inflated owing to a high prevalence of chronic conditions and vaccination in our control population. Similar studies in other settings are needed to confirm or refute our results.

We thank the patients and healthcare workers of the National Institute of Respiratory Diseases for their generous support and cooperation. Contributors: LG-G, JLV-G, and EL-P participated in the study design, data management, and data analysis, and wrote the manuscript. AJ-C, PC-H, $A G-A$, and $B C-A$ participated in the study design and contributed to the analyses. AH-I, EF-G, RB-S, LF-R, SPdeLR, and CA-A contributed to the design and implementation of the study. MHR-L, RP-P, and MH-A made valuable contributions to the study's design, analysis, and writing of the manuscript. All authors reviewed and approved the final manuscript, had full access to all of the data (including statistical reports and tables) in the study, and can take responsibility for the integrity of the data and the accuracy of the data analysis. LG-G and JLV-G are the guarantors. Funding: This study was supported by the Mexican Ministry of Health. The funding source did not influence or participate in the design and conduct of the study; in the collection, management, analysis, and interpretation of the data; in writing the manuscript; or in the decision to submit the article for publication. The researchers were independent of the funder. Competing interests: JLV-G and SPdeLR are employed by Laboratorios de Biológicos y Reactivos de México (BIRMEX).

Ethical approval: This study was approved by the appropriate institutional review boards.

Data sharing: The technical appendix, statistical code, and dataset are available from jvaldespinog@birmex.gob.mx

1 World Health Organization. Influenza A(H1N1)—update 58. 2009. www.who.int/csr/don/2009_07_06/en/index.html.

2 Swine influenza A (H1N1) infection in two children-southern California, March-April 2009. MMWR Morb Mortal Wkly Rep 2009;58:400-2.

3 Update: novel influenza A (H1N1) virus infection-Mexico, MarchMay, 2009. MMWR Morb Mortal Wkly Rep 2009;58:585-9.

4 World Health Organization. Swine flu illness in the United States and Mexico-update 2. 2009. www.who.int/csr/don/2009_04_26/en/ index.html.

5 World Health Organization. Swine flu illness in the United States and Mexico. 2009. www.who.int/csr/don/2009_04_24/en/index.html.

6 National Center for Biotechnology Information. GenBank sequences from 2009 H1N1influenza outbreak. 2009. www.ncbi.nlm.nih.gov/ genomes/FLU/SwineFlu.html.

7 World Health Organization. Vaccines for the new influenza $A(H 1 N 1)$. 2009. www.who.int/csr/disease/swineflu/

frequently_asked_questions/vaccine_preparedness/en/index. html.

8 Gobierno Federal. Manual de Vacunación 2008-2009. www.censia. salud.gob.mx/interior/vacunacion/vacunacion_index.html.

9 Carrillo-Rodriguez JG, Sansores RH, Castrejon A, Perez-Padilla R, Ramirez-Venegas A, Selman M. [Hypersensitivity pneumonitis in Mexico City]. Salud Publica Mex 2000;42:201-7.

10 Perez-Padilla R, de la Rosa-Zamboni D, Ponce de Leon S, Hernandez M, Quinones-Falconi F, Bautista E, et al. Pneumonia and respiratory failure from swine-origin influenza $A(H 1 N 1)$ in Mexico. $N$ Engl / Med 2009;361:680-9.

11 World Health Organization. CDC protocol of realtime RTPCR for influenza A (H1N1). Geneva: WHO, Apr 2009. www.who.int/csr/ resources/publications/swineflu/ CDCRealtimeRTPCR SwineH1Assay-2009 20090430.pdf

12 Orenstein WA, Bernier RH, Hinman AR. Assessing vaccine efficacy in the field. Further observations. Epidemiol Rev 1988;10:212-41.

13 Tumpey TM, Garcia-Sastre A, Taubenberger JK, Palese P, Swayne DE, Basler CF. Pathogenicity and immunogenicity of influenza viruses with genes from the 1918 pandemic virus. Proc Natl Acad Sci USA 2004;101:3166-71.

14 Mogabgab WJ, Leiderman E. Immunogenicity of 1967 polyvalent and 1968 Hong Kong influenza vaccines. JAMA 1970;211:1672-6.

15 Serum cross-reactive antibody response to a novel influenza $A$ (H1N1) virus after vaccination with seasonal influenza vaccine. MMWR Morb Mortal Wkly Rep 2009;58:521-4.

16 Bridges CB, Thompson WW, Meltzer MI, Reeve GR, Talamonti WJ, Cox NJ, et al. Effectiveness and cost-benefit of influenza vaccination of healthy working adults: a randomized controlled trial. JAMA 2000;284:1655-63.

17 Belongia EA, Kieke BA, Donahue JG, Greenlee RT, Balish A, Foust A, et al. Effectiveness of inactivated influenza vaccines varied substantially with antigenic match from the 2004-2005 season to the 2006-2007 season. J Infect Dis 2009;199:159-67.

18 Herrera GA, Iwane MK, Cortese M, Brown C, Gershman K, Shupe A, et al. Influenza vaccine effectiveness among 50-64-year-old persons during a season of poor antigenic match between vaccine and circulating influenza virus strains: Colorado, United States, 2003 2004. Vaccine 2007;25:154-60.

19 Nichol KL, Mendelman PM, Mallon KP, Jackson LA, Gorse GJ, Belshe RB, et al. Effectiveness of live, attenuated intranasal influenza virus vaccine in healthy, working adults: a randomized controlled trial. JAMA 1999;282:137-44.

20 Ohmit SE, Victor JC, Rotthoff JR, Teich ER, Truscon RK, Baum LL, et al. Prevention of antigenically drifted influenza by inactivated and live attenuated vaccines. N Engl J Med 2006;355:2513-22.

21 Ritzwoller DP, Bridges CB, Shetterly S, Yamasaki K, Kolczak M, France EK. Effectiveness of the 2003-2004 influenza vaccine among 
children 6 months to 8 years of age, with 1 vs 2 doses. Pediatrics 2005;116:153-9.

22 Shuler CM, Iwamoto M, Bridges CB, Marin M, Neeman R, Garqiullo P, et al. Vaccine effectiveness against medically attended, laboratoryconfirmed influenza among children aged 6 to 59 months, 20032004. Pediatrics 2007;119:e587-95.

23 Webster RG, Bean WJ, Gorman OT, Chambers TM, Kawaoka Y. Evolution and ecology of influenza A viruses. Microbiol Rev 1992;56:152-79.

24 Hay AJ, Gregory V, Douglas AR, Lin YP. The evolution of human influenza viruses. Philos Trans R Soc Lond B Biol Sci 2001;356:1861-70.

25 Garten RJ, Davis CT, Russell CA, Shu B, Lindstrom S, Balish A, et al. Antigenic and genetic characteristics of swine-origin 2009 A(H1N1) influenza viruses circulating in humans. Science 2009;325:197-201.
26 Leyva-Flores, Kgeyama MK, Evviti-Erice J. How people respond to illness in Mexico: self-care or medical care? Health Policy 2001;57:15-26

27 Barraza-Llorens M, Bertozzi S, Gonzales-Pier E, Gutierrez JP. Addressing inequity in health and healthcare in Mexico. Health Aff (Millwood) 2002;21:47-56.

28 Human infection with new influenza A (H1N1) virus: clinical observations from Mexico and other affected countries, May 2009. Wkly Epidemiol Rec 2009;84:185-9.

29 World Health Organization. WHO recommendations on pandemic (H1N1) 2009 vaccines. www.who.int/csr/disease/swineflu/notes/ h1n1_vaccine_20090713/en/index.html.

Accepted: 18 September 2009 